\title{
Successful Treatment of Bacillus licheniformis Peritonitis in Peritoneal Dialysis Patient with Intraperitoneal Vancomycin: A Case Report
}

This article was published in the following Dove Press journal: International Medical Case Reports Journal

\section{Waleed Albaker}

Department of Internal Medicine, King Fahd Hospital of the University, Imam Abdulrahman Bin Faisal University, AlKhobar, Saudi Arabia
Correspondence: Waleed Albaker Department of Internal Medicine, King Fahd Hospital of the University, Imam Abdulrahman Bin Faisal University, AlKhobar, 40246, Saudi Arabia

Email wialbakr@iau.edu.sa
Abstract: Bacillus licheniformis is a rare pathogen causing peritonitis in peritoneal dialysis (PD) patients, and it is usually recognized among immunosuppressed or traumatized patients. A 24-year-old lady was treated for peritonitis as an outpatient with empirical therapy. PD culture grew Bacillus licheniformis after 48 hours, and she continued receiving intraperitoneal (IP) vancomycin for a total of three weeks. The patient was clinically stable throughout the course of therapy and showed complete resolution of her symptoms. This was the first case of reported Bacillus peritonitis in an automated peritoneal dialysis (APD) patient with rapid clinical and biochemical improvement without evidence of relapse or recurrence.

Keywords: peritonitis, Bacillus licheniformis, automated peritoneal dialysis, APD, vancomycin

\section{Introduction}

Peritonitis is a serious complication of Peritoneal Dialysis (PD). It is the direct contributing factor of death in approximately $16 \%$ of PD patients ${ }^{1}$ and remains the leading cause of hospitalizations, technique failure and conversion to hemodialysis., ${ }^{2,3}$ Therefore, it is paramount to implement all available measures to prevent the occurrence of such complication and to diagnose peritonitis at early stage and apply the appropriate antibiotics in order to limit the serious consequences.

Identifying the organism responsible for peritonitis is a vital outcome determinant. Although gram-positive cocci, mainly S. epidermidis and S. aureus are the most common causes, gram-negative peritonitis is frequently increasing. ${ }^{2}$ Pseudomonas peritonitis is associated with increased frequencies of hospitalization and high rates of catheter removal. ${ }^{1}$ However, less frequent organisms have been involved in the pathogeneses of peritonitis. In this context, we report a case of peritonitis caused by Bacillus licheniformis which is an extremely rare pathogen in peritonitis.

So far, two cases have been reported which were mainly in continuous ambulatory peritoneal dialysis (CAPD) patients. Our case was unique as it was considered the first case of Bacillus peritonitis in an Automated Peritoneal Dialysis (APD) patient and it respond promptly to intra-peritoneal vancomycin.

\section{Case Presentation}

A 24-year-old lady on APD for almost two years secondary to type 1 diabetes mellitus. She was first diagnosed with type 1 diabetes mellitus at the age of 7 . She 
has diabetic proliferative retinopathy and diabetic neuropathy with no previous history of peritonitis. She had two previous admissions 10 years ago due of diabetic ketoacidosis. She presented to our PD Unit on April 2020 with a history of lower abdominal pain for 3-days duration. The pain was moderate in severity, non-radiating, with no relieving or aggravating factors. It was not associated with fever, nausea, vomiting or turbid discoloration of PD fluid. There was no history of urinary symptoms or diarrhea or previous episodes of peritonitis.

The patient was vitally and clinical stable Her physical examination showed blood pressure of $125 / 70 \mathrm{mmHg}$, pulse rate of $90 / \mathrm{min}$, respiratory rate of $18 / \mathrm{min}$ and temperature of $37.8^{\circ} \mathrm{C}$. She has left eye diabetic proliferative retinopathy in addition to bilateral legs neuropathy and dermopathy. Her abdominal examination showed no evidence of hepatosplenomegaly. Her superficial palpation revealed mild tenderness in hypogastric area. The rest of her clinical examinations were unremarkable. Her investigations were normal apart from white blood cell count of $4500 /$ microliter, hemoglobin of $10.6 \mathrm{gm} / \mathrm{dL}$ and glycated hemoglobin of $6.7 \%$. She was well controlled on glargine 20 at bedtime and aspart insulin 3 units with meals.

The PD fluid was clear with no exit site discharge. PD fluid analysis, gram stain and culture were requested, and the patient was treated as a case of peritonitis and $1 \mathrm{gm}$ of ceftriaxone IP and $1 \mathrm{gm}$ of vancomycin IP were given as per our protocol. Her PD fluid analysis confirmed the presence of peritonitis with $\mathrm{WBC}>200$, however, the initial results of PD fluid gram stain and cultures as well as exit site cultures all came negative.

The patient was receiving her daily dose of IP ceftriaxone when the second aerobic culture of the peritoneal fluid confirmed the presence of Bacillus licheniformis. Upon further questioning, she admitted having a cat and a dog at home. The antibiotic regimen was changed to $1000 \mathrm{mg}$ of Vancomycin at 4 days interval and adjusted according to Vancomycin blood level with target of 10-15 mg/liter. The patient recovered completely from her peritonitis and did not develop any recurrence of her peritonitis over 6 months follow up following her course of treatment with Vancomycin.

\section{Discussion}

Peritoneal dialysis infection rates should be monitored and reported for every clinical dialysis program annually. Peritonitis is a common and serious complication of peritoneal dialysis. Although less than $5 \%$ of peritonitis episodes resulted in death, peritonitis is the direct or major contributing cause of death in around $16 \%$ of PD patients. $^{7-12}$ In addition, severe or prolonged peritonitis leads to structural and functional alterations of the peritoneal membrane, eventually leading to membrane failure. The overall peritonitis rate should not exceed 0.5 episodes per year at risk.

In some outstanding centers, peritonitis rates as low as 0.18 to 0.20 episodes per year have been reported. ${ }^{13}$ Additionally, the PD team comprised of physicians and nurses, should review the presumed etiology, causative organisms, and antibiotic sensitivity of each infection. When infection rates are increasing or undesirably high, interventions should be employed. The updated 2016 guidelines recommended that every program should monitor and record peritonitis incidence, the overall rate of peritonitis, rates of specific organisms, percentage of patients who are peritonitis free, and susceptibilities yearly.

The guidelines suggested using a standard number of episodes per patient-year for reporting and also those absolute rates should be reported as part of a continuous quality improvement (CQI) program. ${ }^{7}$ The purpose of data documentation is to evaluate the program's treatment regimen and to facilitate the best possible outcomes for patients.

Bacillus licheniformis is an aerobic, gram-positive, spore-forming rod, and is ubiquitous in the environment. ${ }^{6}$ Bacillus organisms are usually found in the soil, dust, vegetables and water, and some species are part of the normal gut flora. It is increasingly recognized as a human pathogen that causes severe infections in debilitated, immunocompromised, or traumatized patients. ${ }^{4}$ It was isolated in cases with bacteremia, peritonitis, food poisoning, and eye infections. ${ }^{6}$ The incidence of PD peritonitis caused by Bacillus species was not known and has not been previously reported. Park et al, has reported relapsing peritonitis in CAPD patient due to Bacillus licheniformis initially was treated with Tobramycin and Cefazolin with partial improvement and the peritonitis relapsed after five days from discontinuation of antibiotic, the relapsing peritonitis responded well to intra-peritoneal Vancomycin for three weeks without catheter removal similar to our case. ${ }^{4}$

To the best of our knowledge, two cases have been previously reported in the literature confirming Bacillus licheniformis Peritonitis and it is considered a rare pathogen in peritoneal dialysis. ${ }^{4,5}$ Table 1 showed the demographics and outcomes of all cases. As Bacillus species are common contaminants on culture media and physicians may consider these species as non-pathogens. However, 
Table I Comparison of the Three Cases

\begin{tabular}{|c|c|c|c|}
\hline & Case I & Case 2 & Case 3 \\
\hline Date of Publication & 2001 & 2006 & 2021 \\
\hline Age & 56 & 31 & 24 \\
\hline Sex & Female & Male & Female \\
\hline Co-morbid condition & DM & HTN & DM \\
\hline PD Modality & CAPD & CAPD & APD \\
\hline Antibiotic & $\begin{array}{l}\text { Netilmicin and } \\
\text { Cefotiam }\end{array}$ & $\begin{array}{l}\text { Initially tobramycin and cefazolin, relapsed Vancomycin } 3 \\
\text { week }\end{array}$ & $\begin{array}{l}\text { Igm of Vancomycin } 3 \\
\text { week }\end{array}$ \\
\hline Previous peritonitis & 3 & Unknown & 0 \\
\hline $\begin{array}{l}\text { Resolution of Peritonitis/ } \\
\text { Outcome }\end{array}$ & Rapid Improvement & Relapse & Rapid improvement \\
\hline
\end{tabular}

Abbreviations: DM, diabetes mellitus; CAPD, continuous ambulatory peritoneal dialysis; APD, automated peritoneal dialysis.

in the presence of clinical symptoms and signs with peritoneal fluid more than $100 / \mathrm{uL}$; peritonitis should be taken seriously and managed promptly. Due to dramatic response to Vancomycin therapy in our case and Park et $\mathrm{al}^{4}$ we therefore highly recommend that in case of Bacillus licheniformis peritonitis in peritoneal dialysis, glycopeptide antibiotic should be the drug of choice.

Vancomycin is a unique glycopeptide antibiotic that works through a special mechanism of action by inhibiting the bacterial cell wall synthesis that prevents the incorporation of N- acetylmuramic acid and $\mathrm{N}$-acetylglucosamine peptide from being incorporated into peptidoglycan.

In conclusion, in our case treatment of Bacillus licheniformis Peritonitis using Intraperitoneal Vancomycin was proved to be safe, effective and highly successful.

\section{Ethical Approval}

Ethical approval was obtained from Imam Abdulrahman bin Faisal University Review Board of Medical Center, and written consents were taken from the patients.

Furthermore, "Informed consent was obtained from the patient to publish their case details and any accompanying images (if any)."

\section{Acknowledgment}

The authors are pleased to express their great gratitude and appreciation to the peritoneal dialysis nurses at King Fahad University Hospital in Al Khobar for their valuable support during the patient's course of therapy and follow-up.

\section{Funding}

The author received no financial support for the research, authorship, and/or publication of this article.

\section{Disclosure}

The author declared no potential conflicts of interest with respect to the research, authorship, and/or publication of this article.

\section{References}

1. Li PK-T, Szeto CC, Piraino B, et al. ISPD peritonitis recommendations: 2016 update on prevention and treatment. Peritoneal Dialysis Int. 2016;36(5):481-508.

2. Voinescu CG, Khanna R. Peritonitis in peritoneal dialysis. The Int $J$ of Artificial Ogans. 2002;25(4):249-260. doi:10.1177/03913988020250 0402

3. Segal JH, Messana JM. Prevention of peritonitis in peritoneal dialysis. Int Seminars Dialysis. 2013;4(26):494-502. doi:10.1111/sdi.12114

4. Park DJ, Yun JC, Baek JE, et al. Relapsing Bacillus licheniformis peritonitis in a continuous ambulatory peritoneal dialysis patient (Case Report). Nephrol. 2006;11(1):21-22.

5. Ryoo NH, Chun HJ, Jeon DS, Kim JR, Park SB. Bacillus licheniformis peritonitis in a CAPD patient. Peritoneal Dialysis Int. 2001;21(1):1. doi:10.1177/089686080102100122

6. Haydushka IA, Markova N, Kirina V, Atanassova M. Recurrent sepsis due to Bacillus licheniformis. J Global Infect Dis. 2012;4(1):82. doi:10.4103/0974-777X.93768

7. Ghali JR, Bannister KM, Brown FG, et al. Microbiology and outcomes of peritonitis in Australian peritoneal dialysis patients. Perit Dial Int. 2011;31:651-662. doi:10.3747/pdi.2010.00131

8. Pérez Fontan M, Rodríguez-Carmona A, García-Naveiro R, Rosales M, Villaverde P, Valdés F. Peritonitis-related mortality in patients undergoing chronic peritoneal dialysis. Perit Dial Int. 2005;25:274-284. doi:10.1177/089686080502500311

9. Davenport A. Peritonitis remains the major clinical complication of peritoneal dialysis: the London, UK, peritonitis audit 2002-2003. Perit Dial Int. 2009;29:297-302. doi:10.1177/089686080902900314 
10. Szeto CC, Wong TY, Chow KM, Leung CB, Li PK. Are peritoneal dialysis patients with and without residual renal function equivalent for survival study? Insight from a retrospective review of the cause of death. Nephrol Dial Transplant. 2003;18:977-982. doi:10.1093/ndt/ gfg027

11. Brown MC, Simpson K, Kerssens JJ, Mactier RA. Peritoneal dialysis-associated peritonitis rates and outcomes in a national cohort are not improving in the post-millennium (2000-2007). Perit Dial Int. 2011;31:639-650. doi:10.3747/pdi.2010.00185
12. Boudville N, Kemp A, Clayton P, et al. Recent peritonitis associates with mortality among patients treated with peritoneal dialysis. $J \mathrm{Am}$ Soc Nephrol. 2012;23:1398-1405. doi:10.1681/ASN.2011121135

13. Li PK-T, Szeto CC, Piraino B, et al. ISPD Peritonitis Recommendations: 2016 Update on Prevention and Treatment. Perit Dial Int. 2016;36:481-508.

\section{Publish your work in this journal}

The International Medical Case Reports Journal is an international, peer-reviewed open-access journal publishing original case reports from all medical specialties. Previously unpublished medical posters are also accepted relating to any area of clinical or preclinical science. Submissions should not normally exceed 2,000 words or 4 published pages including figures, diagrams and references. The manuscript management system is completely online and includes a very quick and fair peer-review system, which is all easy to use. Visit http://www.dovepress.com/testimonials.php to read real quotes from published authors. 